IVIG Control Event No event Event No event

Placebo + standard care

Gharebaghi 2020

Heterogeneity: $\mathrm{I}^{2}=0.00 \%, \mathrm{H}^{2}=1.00$

Test of $\theta_{i}=\theta_{i}: Q(0)=0.00, p=$.

\section{Standard care}

Sakoulas 2020

Heterogeneity: $I^{2}=100.00 \%, H^{2}=1.00$

Test of $\theta_{i}=\theta_{j}: Q(0)=0.00, p=$.

\section{Overall}

Heterogeneity: $\mathrm{I}^{2}=0.00 \%, \mathrm{H}^{2}=1.00$

Test of $\theta_{i}=\theta_{j}: Q(1)=0.02, p=0.89$

Test of group differences: $Q_{b}(1)=0.02, p=0.89$

Fixed-effects Mantel-Haenszel model
Risk Ratio Weight

with $95 \% \mathrm{Cl}$

$0.41[0.18,0.93] 83.03$

$0.41[0.18,0.93]$

$0.35[0.04,3.06] 16.97$

$0.35[0.04,3.06]$

$0.40[0.19,0.87]$

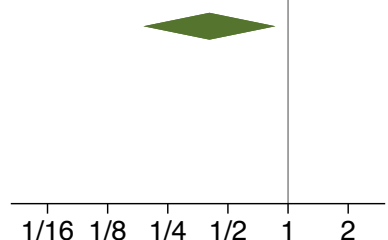

